\title{
Flexural and Compressive Strength of Concrete Tiles with Different Levels of Partial Substitution of Pulverized Solid Waste Materials for Gravel
}

\author{
Benjamin D. Varela, Jean Lee S. Quito, Noe C. Piaza \\ Institute of Land and Water Resources Management, College of Agriculture, University of Eastern Philippines, \\ Catarman, The Philippines \\ Email: benjaminvarela63@yahoo.com, varelabenjamin63@gmail.com
}

Received 8 November 2014; revised 17 December 2014; accepted 5 January 2015

Copyright (C) 2015 by authors and OALib.

This work is licensed under the Creative Commons Attribution International License (CC BY). http://creativecommons.org/licenses/by/4.0/

(c) (i) Open Access

\begin{abstract}
A factorial experiment in completely randomized design with three (3) replications was employed in this study. Gravel was partially substituted with two (2) kinds of pulverized solid waste materials at three (3) levels of substitutions: $15 \%$ (LS2) and 30\% (LS3) and $45 \%$ (LS4). This study had a total of twelve (12) experimental treatment combinations to include a control treatment (LS1 with 0 partial substitution) for purposes of comparison. The results of this study generally showed that the partial substitution of pulverized solid waste material for gravel significantly lowered the flexural and compressive strengths of concrete tiles. The concrete tiles with $15 \%$ (LS2) partial substitution had the highest average flexural and compressive strengths, while the tiles with 45\% (LS4) partial substitution had the lowest average values. As to the type of solid waste material, the study revealed that the concrete tiles with pulverized clear-plastic solid waste materials had numerically higher flexural and compressive strengths than those concrete tiles with pulverized aluminized plastic solid waste material for gravel. The researchers concluded that the partial substitution of pulverized solid waste materials for gravel significantly lowered the flexural and compressive strengths of the concrete tiles.
\end{abstract}

\section{Keywords}

Partial Substitution, Flexural Strength, Compressive Strength, Pulverized Solid Waste Materials

Subject Areas: Agricultural Engineering, Civil Engineering, Environmental Engineering 


\section{Introduction}

Rapid increase of population contributes to the increase of pollution in a large proportion. The affluent lifestyle brought about by modernization and development heightens the problem of solid waste management. Many solid waste materials produced today will remain in the environment for hundreds and, perhaps, thousands of years. The creation of non-decaying solid waste materials, combined with the growing consumer population, has resulted in a waste disposal crisis. One solution to this crisis lies in recycling solid wastes into useful products again.

In the Philippines, solid waste management is a major environmental concern. Solid waste materials are generated daily from manufacturing processes, service industries, community activities and agricultural production systems. A lot of solid waste materials scattered in our surroundings such as rice hull, saw dust, coconut husk, old rubber tires, plastic containers, cellophane bags, and many more may be recycled. One way of recycling is to mix them in concrete products used in non-critical structures, like farm structures.

Farm structures are usually made of concrete; hence, are very expensive structures. The cost of these structures, however, can be reduced using concrete products made from concrete mixed with solid waste materials. The mixing of solid waste materials in concrete will make the production of concrete products cheaper.

In this study, a new kind of construction material has been developed which can be used for farm structures and other low load-bearing structures.

\section{Objectives}

Initially, this study was conducted to know only the effect (decrease/increase) of the mixing of pulverized solid waste materials in the production of concrete tiles on the flexural and compressive strengths and the material cost of concrete tiles. Specifically, this study was aimed to:

- Measure the flexural and compressive strengths of concrete tiles made from concrete with different levels of partial substitution of pulverized solid waste materials for gravel;

- Identify in what treatment combination/s (type of pulverized solid waste materials and level of partial substitution) the flexural and compressive strengths of concrete tiles with pulverized solid waste materials are not significantly lower as compared to those of the concrete tiles of the control treatment;

- Derive a functional relationship between the flexural and compressive strengths of concrete tiles and the different levels of partial substitution of pulverized solid waste materials for gravel; and

- Find out whether the partial substitution of pulverized solid waste materials for gravel in concrete tiles is economical and/or beneficial.

\section{Review of Related Literature}

Derucher [1] stated that concrete is used in many ways and is subjected to a variety of loading conditions; hence, different types of stresses develop. He revealed that very often the dominant stresses are compressive in nature, since the material has long been known to exhibit its best strength characteristics when subjected to compressive loading. The compressive strength of concrete, one of the most important and useful properties, is indicated by the unit stress required to cause the failure of a specimen, he clarified.

Heiger [2] stated that lightweight concrete are usually made from aggregates conforming to ASTM C330 produced artificially in a kiln, such as aluminized plastics, expanded clays, and shales. Reynolds et al. [3] averred that an admixture may be added to concrete mixes in small quantities but a high degree of control should be exercised. He stressed that the admixture can modify the properties of the hardened concrete. Shehata et al. [4], in a study on the use of solid waste materials as fine aggregates substitute in concrete, concluded that granulated waste materials, such as plastics, glass, and fiberglass can be used in cementitious concrete composites without seriously hindering its mechanical properties up to composition range of $20 \%$.

As to composition, concrete blocks/tiles are often made of 1:3:6 concrete with a maximum size aggregate of $10 \mathrm{~mm}$ or a cement-sand mixture of 1:7, 1:8 or 1:9. These mixtures, if properly cured, give concrete blocks/tiles a compression strength well above what is required in a one-storey building. It is indicated that pavers (tiles) should have a minimum thickness of $38 \mathrm{~mm}$, and a standard thickness of $60 \mathrm{~mm}$ for light traffic and $80 \mathrm{~mm}$ for heavy traffic, though it is commonly $50 \mathrm{~mm}$ thick [5]. 


\section{Methodology}

\subsection{Materials}

In the conduct of this research activity, the researchers used the following materials:

\begin{tabular}{ccccc}
\hline MATERIAL & QUANTITY & UNIT & UNIT COST (PhP) & AMOUNT (PhP) \\
Washed Sand & 0.50 & $\mathrm{~m}^{3}$ & 300.00 & 150.00 \\
Pulverized Plastics & 0.07 & $\mathrm{~m}^{3}$ & 0.00 & 0.00 \\
Portland Cement (40 kg/bag) & 1 & $\mathrm{bag}$ & 215.00 & 215.00 \\
Gravel & 0.50 & $\mathrm{~m}^{3}$ & 900.00 & 450.00 \\
Plain G.I. Sheet (8' $\times$ 3') & 4 & $\mathrm{sht}$ & 60.00 & 15.00 \\
Common Wire Nail (1.5”) & $1 / 4$ & $\mathrm{~kg}$ & $\mathbf{1 6 9 0 . 0 0}$ \\
\hline
\end{tabular}

\subsection{Research Design}

The $2 \times 3$ factorial experiments in a completely randomized design (CRD) with three (3) replications was used to quantify the effect of the partial substitution of pulverized solid waste materials for the coarse aggregate in concrete tiles. The experiments involved three (3) levels of partial substitution (LS2-15\%, LS3-30\%, LS4$45 \%$ ) and two (2) types of solid waste materials (PPW—-pulverized plastic wrappers and PAW—pulverized aluminized wrappers). The LS1 ( $0 \%$ or no substitution) served as the control treatment. Hence, there were twelve (12) treatment combinations in this study, as shown in Figure 1.

The mixing proportions of the concrete tiles for the different levels of partial substitution are given in Table 1 .

\subsection{Experimental Procedures}

\subsubsection{The Production of Pulverized Solid Waste Materials (SWM)}

Plastic and aluminized wrappers were gathered from households and from waste disposal areas. They were cleaned and sundried. They were pulverized using a pulverizing machine from Victoria, Northern Samar.

\subsubsection{The Production of Concrete Tiles}

The concrete tiles were made following the set of procedures enumerated below:

- Tile molders, measuring $150 \mathrm{~mm} \times 150 \mathrm{~mm} \times 60 \mathrm{~mm}$, were fabricated using plain GI sheets.

- The different concrete aggregates and the pulverized SWM were mixed using the different mixing proportions. A water: cement ratio of 5 gallons per bag was adopted for all treatment combinations.

- After thorough and even mixing, the concrete mixture was poured into the fabricated tile molders.

- Excess concrete mixture was scraped off the top surface of the molder. The molders filled with concrete mixture were covered with plywood to prevent immature hardening of the concrete tile.

- The molders filled with concrete mixture were placed on a rigid horizontal surface for 24 hours. After which, the hardened concrete tiles were removed from the molders.

- The concrete tiles were exposed to air for one (1) day and cured for 28 days by submerging them in water.

\subsubsection{The Flexural and Compressive Strength Testing of Concrete Tiles}

After the 28-day curing period, the concrete tiles were subjected to flexural and compressive strength tests at the Materials' Testing Center of the City Engineering Office (CEO), Calbayog City, Samar, using a Universal Testing Machine (UTM).

\subsubsection{The Statistical Analyses}

This study employed both the numerical comparison and the statistical techniques. The numerical comparison technique was used to compare the average flexural and compressive strengths of concrete tiles. The F-Test (ANOVA) was used to ascertain whether the numerical differences in the average flexural and compressive 
Table 1. The proportions of concrete-pulverized SWM mixtures used in the different levels of substitution in this study.

\begin{tabular}{cccccc}
\hline \multirow{2}{*}{$\begin{array}{c}\text { Levels of } \\
\text { Substitution }\end{array}$} & \multicolumn{4}{c}{ Volume of Concrete Aggregates (cu. ft.) } & $\begin{array}{c}\text { Mixing } \\
\text { Proportions }\end{array}$ \\
\cline { 2 - 5 } & Cement & Sand & Gravel & SW Material* & $1: 3: 6$ \\
LS1 (0\%) & 1 & 3 & 6.0 & 0.00 & $1: 3: 5.1: 0.9$ \\
LS2 (15\%) & 1 & 3 & 5.1 & 0.90 & $1: 3: 4.2: 1.8$ \\
LS3 (30\%) & 1 & 3 & 4.2 & 1.80 & $1: 3: 3.3: 2.7$ \\
\hline LS4 (45\%) & 1 & 3 & 3.3 & 2.70 & \\
\hline
\end{tabular}

Note: ${ }^{*}$ This could be either pulverized plastic or aluminized wrappers.

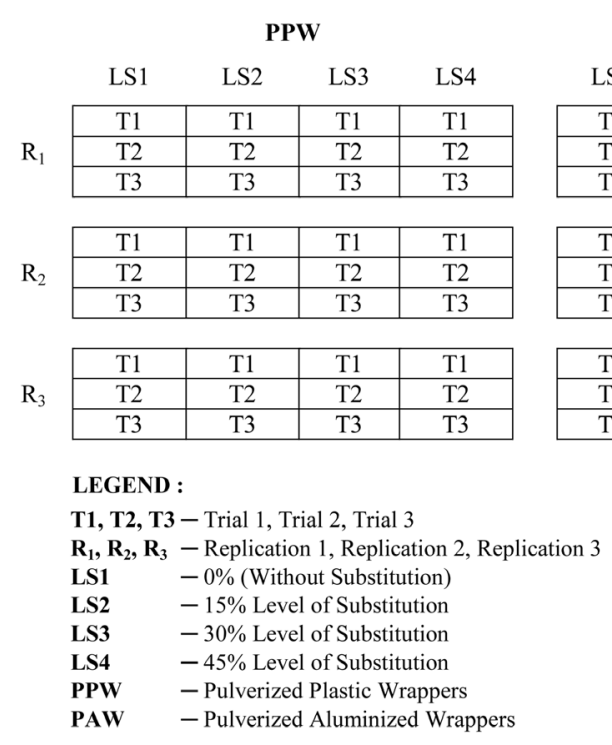

Figure 1. Experimental layout.

strengths and the average material cost of concrete tiles at different treatment combinations are significantly different. Finally, linear and non-linear regression methods were fitted into the experimental data to derive a relationship between the flexural and compressive strengths of concrete tiles and the levels of partial substitution of pulverized solid waste materials.

\subsubsection{The Benefit Cost Analyses}

Using the prevailing prices of the concrete aggregates and some important assumptions, the material cost of concrete tiles for the different treatment combinations were estimated.

\section{Results and Discussion}

\subsection{Flexural Strength}

\subsubsection{The Flexural Strength of Concrete Tiles}

The average flexural strength of concrete tiles with different levels of partial substitution of pulverized solid waste materials for gravel ranged $0.893 \mathrm{MPa}$ (LS1 or 0 substitution) to $0.367 \mathrm{MPa}$ (LS4 or $45 \%$ partial substitution) and $0.893 \mathrm{MPa}$ (LS1) to $0.243 \mathrm{MPa}$ (LS4) as shown in Table 2.

The analysis of variance revealed that the variation in the average flexural strength among treatments is highly significant. The LS1 concrete tiles had the highest average flexural strength while the LS4 concrete tiles had the lowest. This simply means that the substitution of pulverized solid waste materials for gravel significantly weakened the concrete tiles.

The DMRT results indicated that the average flexural strengths of the tiles made from pure concrete $(0 \%$ 
Table 2. The average flexural strength of concrete tiles with different levels of partial substitution of pulverized plastic wrappers for gravel.

\begin{tabular}{ccc}
\hline \multirow{2}{*}{$\begin{array}{c}\text { Treatments } \\
\text { (Levels of } \\
\text { Substitution, \%) }\end{array}$} & \multicolumn{2}{c}{ Average Flexural Strength (MPa) ${ }^{* *}$ of Concrete Tiles } \\
\hline 0 (LS1) & With Pulverized Aluminized Plastic Wrappers & With Pulverized Clear Plastic Wrappers \\
\hline 15 (LS2) & $0.893^{\mathrm{a}}$ & $0.893^{\mathrm{a}}$ \\
30 (LS3) & $0.398^{\mathrm{b}}$ & $0.505^{\mathrm{b}}$ \\
45 (LS4) & $0.378^{\mathrm{bc}}$ & $0.414^{\mathrm{bc}}$ \\
\hline
\end{tabular}

** Averages followed by a common letter are not significantly different at $5 \%$ level of significance.

substitution) and the concrete mixture with $15 \%$ partial substitution of pulverized solid waste materials for gravel are significantly different. Actually, with just $15 \%$ partial substitution, the average flexural strength of the concrete tiles with pulverized clear plastic wrappers was reduced by $0.388 \mathrm{MPa}(43.45 \%)$ while the average flexural strength of those with pulverized aluminized plastic wrappers was reduced by $0.495 \mathrm{MPa}(55.43 \%)$.

This findings show that the level of partial substitution of pulverized solid waste material for gravel strongly reduced the flexural strength of concrete tiles.

\subsubsection{The Comparison of the Treatment Combinations}

Table 3 presents the average flexural strengths of concrete tiles of the different treatment combinations. The table shows that the average flexural strengths of concrete tiles with partial substitution of pulverized solid waste materials for gravel are all significantly lower than that for the control treatment (LS1). However, the concrete tiles with 15\% and 30\% partial substitution of pulverized clear plastic wrappers (LS2 + PCW \& LS3 + PCW) have significantly higher average flexural strength than the other treatment combinations.

\subsubsection{Relationship of Flexural Strength and the Level of Partial Substitution of Pulverized Solid Waste Materials for Gravel}

The data gathered on the average flexural strength of concrete tiles with different levels of partial substitution of pulverized aluminized plastic wrappers were found to best fit the non-linear function:

$$
Y=\alpha+\beta X^{1 / 3}
$$

that can be linearized into:

$$
Y=\alpha+\beta Z
$$

where $Z=X^{1 / 3}$.

The equation derived relating the pulverized aluminized plastic wrapper to the average flexural strength of concrete tiles $\left(A F S_{P A W}\right)$ at the different levels of partial substitution $(L s)$ is:

$$
A F S_{\text {PAW }}=0.51-0.1563 L \mathrm{~s}^{1 / 3}
$$

where $A F S_{P A W}$ is the average flexural strength of the concrete tiles at different levels of partial substitution of pulverized solid waste materials for gravel, with a correlation coefficient of 0.9696 . The observed and estimated (computed using Equation (1)) average flexural strengths of concrete tiles were plotted against the level of partial substitution of pulverized aluminized plastic wrappers for gravel in Figure 2.

The equations relating the substitution level of pulverized clear plastic wrappers for gravel to the average flexural strength of concrete tiles $\left(A F S_{P C W}\right)$ at the different levels of partial substitution $(L s)$ is:

$$
A F S_{P C W}=0.87-0.1718 L s^{1 / 3}
$$

where $A F S_{P C W}$ is the average flexural strength of the concrete tiles at different levels of partial substitution of pulverized solid waste materials for gravel, with a correlation coefficient of 0.987 . The observed and estimated (computed using Equation (2)) average flexural strength of concrete tiles were plotted against the level of partial substitution of pulverized clear plastic wrappers for gravel in Figure 3. 
Table 3. The average flexural strength of concrete tiles of the different treatment combinations.

\begin{tabular}{cc}
\hline Treatment Combinations & Average Flexural Strength (MPa) ${ }^{* *}$ \\
\hline LS1 (Control) & $0.893^{\mathrm{a}}$ \\
LS2 + PCW & $0.505^{\mathrm{b}}$ \\
LS3 + PCW & $0.414^{\mathrm{c}}$ \\
LS2 + PAW & $0.393^{\mathrm{cd}}$ \\
LS3 + PAW & $0.387^{\mathrm{de}}$ \\
LS4 + PAW & $0.367^{\mathrm{de}}$ \\
LS4 + PCW & $0.243^{\mathrm{ef}}$ \\
\hline
\end{tabular}

${ }^{* *}$ Averages followed by a common letter are not significantly different at $5 \%$ level of significance.

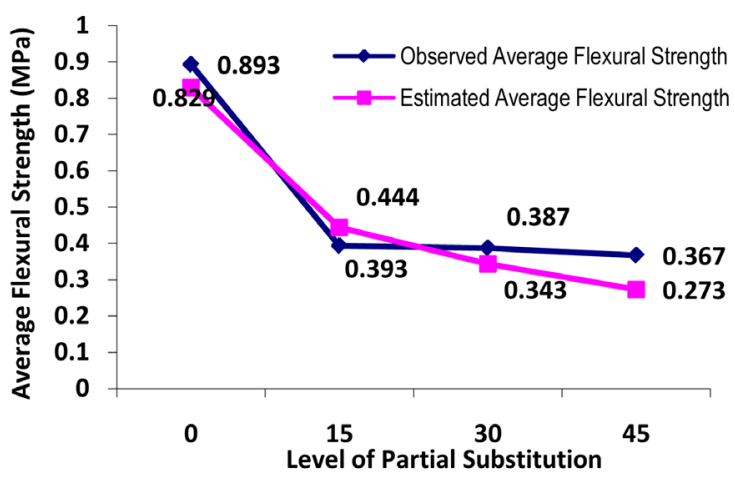

Figure 2. Graph of the average flexural strength of concrete tiles versus the levels of partial substitution of pulverized aluminized plastic wrappers.

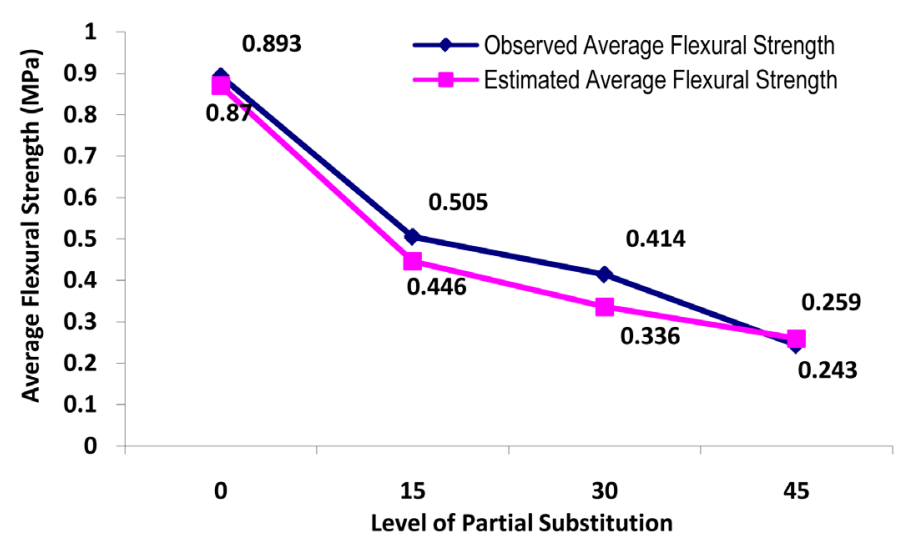

Figure 3. Graph of the average flexural strength of concrete tiles versus the levels of partial substitution of pulverized clear plastic wrappers.

\subsection{Compressive Strength}

\subsubsection{The Compressive Strength of Concrete Tiles}

The average compressive strength of concrete tiles with different levels of partial substitution of pulverized plastic wrappers for gravel ranged $0.392 \mathrm{MPa}$ (LS1 or 0 substitution) to $0.100 \mathrm{MPa}$ (LS4 or $45 \%$ partial substitution) as shown in Table 4.

The DMRT results indicated that the average compressive strengths of the concrete tiles without substitution (LS1 or control) and those with different levels of partial substitution of pulverized solid waste materials for 
Table 4. The average compressive strength of concrete tiles with different levels of partial substitution of pulverized plastic wrappers for gravel.

\begin{tabular}{ccc|}
\hline $\begin{array}{c}\text { Treatments } \\
\text { (Levels of } \\
\text { Substitution, \%) }\end{array}$ & \multicolumn{2}{c|}{$\begin{array}{c}\text { Average Compressive Strength (MPa) } \\
\text { ** }\end{array}$} \\
\hline 0 (LS1) & $\begin{array}{c}\text { Concrete Tiles with Pulverized } \\
\text { Aluminized Plastic Wrappers }\end{array}$ & $\begin{array}{c}\text { Concrete Tiles with Pulverized } \\
\text { Clear Plastic Wrappers }\end{array}$ \\
15 (LS2) & $0.392^{\mathrm{a}}$ & $0.392^{\mathrm{a}}$ \\
30 (LS3) & $0.262^{\mathrm{b}}$ & $0.328^{\mathrm{b}}$ \\
45 (LS4) & $0.164^{\mathrm{bc}}$ & $0.132^{\mathrm{bc}}$ \\
\hline
\end{tabular}

${ }^{* *}$ Averages followed by a common letter are not significantly different at $5 \%$ level of significance.

gravel were significantly different. However, the average compressive strength of concrete tiles with $15 \%$ and $30 \%$, and the $30 \%$ and $45 \%$ partial substitutions of pulverized solid waste materials for gravel are not significantly different. These results show that the partial substitution of pulverized solid waste materials decreased the average compressive strength.

Table 4 showed that the incremental decreases of the average compressive strength of the concrete tiles with $15 \%$ partial substitution of pulverized aluminized plastic and clear plastic wrappers for gravel in concrete mix are $56.62 \%$ and $54.705 \%$, respectively. These data simply shows that even just a $15 \%$ partial substitution for gravel can greatly affect (decrease) the compressive strength of concrete tiles.

\subsubsection{The Comparison of the Treatment Combinations}

Table 5 presents the average compressive strengths of concrete tiles of the different treatment combinations. It shows that the average compressive strengths of concrete tiles with partial substitution of pulverized solid waste materials for gravel are all significantly lower than that for the control treatment (LS1) except for LS2 + CPW treatment. It also shows that the average compressive strength of the concrete tiles with partial substitution of both pulverized solid waste materials (PAW, PCW) at the same levels (15\%, 30\%, 45\%) for gravel are not significantly different.

\subsubsection{Relationship of Compressive Strength and the Level of Partial Substitution of Pulverized Solid Waste Materials for Gravel}

The relationships between the data gathered on the average compressive strength of concrete tiles with different levels of partial substitution of pulverized solid waste materials were found to best fit the non-linear function:

$$
1 / Y=\alpha+\beta X
$$

that can be linearized into:

$$
Y^{\prime}=\alpha+\beta Z
$$

where $Z=X$ and $Y^{\prime}=1 / Y$.

The equation derived relating the average compressive strength of concrete tiles $\left(A C S_{P A W}\right)$ at the different levels of partial substitution $(L s)$ of pulverized aluminized plastic wrappers is :

$$
1 / \text { ACS }_{\text {PAW }}=1.88+0.1668 \mathrm{Ls}
$$

where $A C S_{P A W}$ is the average compressive strength of the concrete tiles at different levels of partial substitution of pulverized aluminized plastic wrappers for gravel, with a correlation coefficient of 0.97 . The observed and estimated (computed using Equation (3)) average compressive strengths of concrete tiles were plotted against the level of partial substitution of pulverized aluminized plastic wrappers for gravel in Figure 4.

The equations derived relating the substitution level of pulverized clear plastic wrappers for gravel to the average compressive strength of concrete tiles $\left(A C S_{P C W}\right)$ at the different levels of partial substitution $(L s)$ is:

$$
1 / A S_{P C W}=1.587+0.1821 L s
$$

where $A C S_{P C W}$ is the average compressive strength of the concrete tiles at different levels of partial substitution of pulverized clear plastic wrappers for gravel, with a correlation coefficient of 0.963 . The observed and esti- 
Table 5. The average compressive strength of concrete tiles of the different treatment combinations.

\begin{tabular}{cc}
\hline Treatment Combinations & Average Flexural Strength (MPa) ${ }^{* *}$ \\
\hline LS1 (Control) & $0.394^{\mathrm{a}}$ \\
LS2 + PCW & $0.328^{\mathrm{ab}}$ \\
LS2 + PAW & $0.262^{\mathrm{bc}}$ \\
LS3 + PAW & $0.164^{\mathrm{bc}}$ \\
LS3 + PCW & $0.132^{\mathrm{cd}}$ \\
LS4 + PAW & $0.100^{\mathrm{d}}$ \\
LS4 + PCW & $0.100^{\mathrm{d}}$ \\
\hline
\end{tabular}

${ }^{* *}$ Averages followed by a common letter are not significantly different at $5 \%$ level of significance.

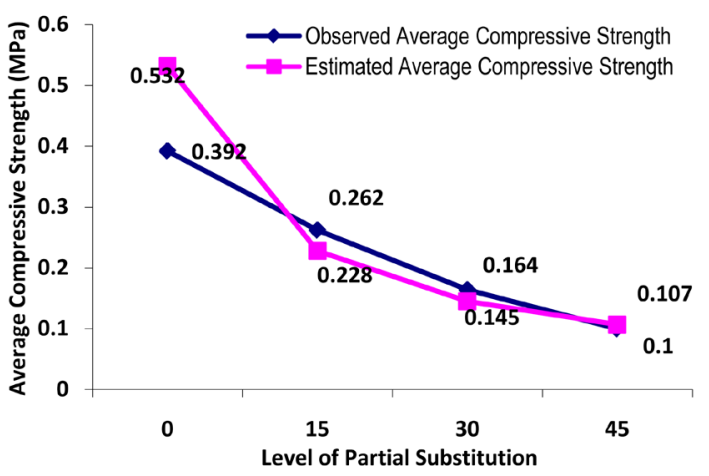

Figure 4. Graph of the average compressive strength of concrete tiles versus the levels of partial substitution of pulverized aluminized plastic wrappers.

mated (computed using Equation (4)) average compressive strength of concrete tiles were plotted against the level of partial substitution of pulverized clear plastic wrappers for gravel in Figure 5.

\subsection{Benefit/Cost Analysis}

\subsubsection{The Prices of the Experimental Materials}

The prices of the concrete aggregates and pulverized solid waste materials used in the conduct of a simple benefit/cost analysis to find out whether the partial substitution of pulverized solid waste material for gravel is economical are given below:

- Cost of cement was P 215.00 per bag;

- Cost of sand was P 300.00 per cubic meter;

- Cost of gravel was P 900.00 per cubic meter;

- Pulverized solid waste material was free of charge;

- Water was free of charge.

\subsubsection{The Material Cost of Concrete Tiles of the Different Treatment Combinations}

The cost per cubic meter of concrete mixture with $0,15 \%, 30 \%$ and $45 \%$ partial substitution of pulverized solid waste materials for gravel were computed to be PhP 2459.50; 2316.10; 2172.60; and 2029.15, respectively.

The data in Table 6 show that substitution can reduce the cost of concrete tile by as much as 10 centavos each for every $15 \%$ increase in the partial substitution of pulverized solid waste materials for gravel.

\section{Conclusions and Recommendations}

\subsection{Conclusions}

Based on the results of the study, the following conclusions were drawn: 
Table 6. The average material cost per cubic meter concrete mixture and the average cost of concrete tile for the different partial substitution treatments.

\begin{tabular}{|c|c|c|c|c|}
\hline $\begin{array}{l}\text { Levels of Partial } \\
\text { Substitution (\%) }\end{array}$ & $\begin{array}{l}\text { Average Material Cost of } \\
\text { Concrete }\left(\mathrm{PhP} / \mathrm{m}^{3}\right)^{*}\end{array}$ & $\begin{array}{l}\text { Estimated Cost of } \\
\text { Concrete Tile (PhP) }\end{array}$ & $\begin{array}{l}\text { Cost (PhP) of Concrete } \\
\text { Paver/Tile (UEP made) }\end{array}$ & $\begin{array}{c}\text { Margin } \\
\text { for Profit (PhP) }\end{array}$ \\
\hline LS1 (0\%) & $2459.50^{\mathrm{a}}$ & 3.50 & 13.00 & 9.50 \\
\hline LS2 (15\%) & $2316.10^{\mathrm{b}}$ & 3.30 & 13.00 & 9.70 \\
\hline LS3 (30\%) & $2172.60^{\text {bc }}$ & 3.10 & 13.00 & 9.90 \\
\hline LS4 (45\%) & $2029.15^{\mathrm{d}}$ & 2.90 & 13.00 & 10.10 \\
\hline
\end{tabular}

*Averages followed by a common letter are not significantly different at $5 \%$ level of significance. ${ }^{* *}$ Computed by dividing the average material cost of concrete mix by 700 (the estimated number of concrete tiles that can be made out of 1 cubic meter concrete mix).

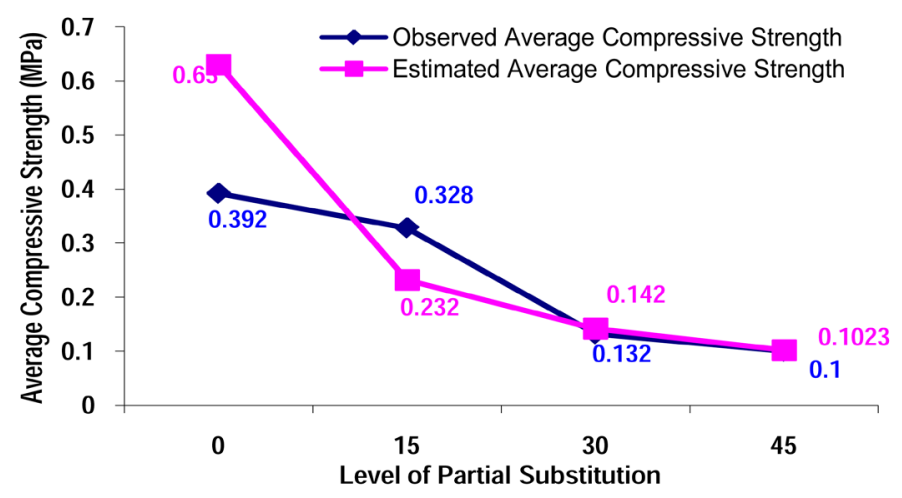

Figure 5. Graph of the average compressive strength of concrete tiles versus the levels of partial substitution of pulverized clear plastic wrappers.

- The concrete tiles with $15 \%, 30 \%$ and $45 \%$ partial substitution of pulverized clear plastic wrappers had average flexural strengths of $0.505,0.414$ and $0.243 \mathrm{MPa}$, respectively. On the other hand, the concrete tiles with $15 \%, 30 \%$ and $45 \%$ partial substitution of pulverized aluminized plastic wrappers had average flexural strengths of $0.393,0.387$, and $0.367 \mathrm{MPa}$, respectively. Generally, the flexural strengths of concrete tiles decreased as the level of partial substitution of pulverized solid waste materials for gravel was increased.

- The concrete tiles with $15 \%, 30 \%$ and $45 \%$ partial substitution of pulverized clear plastic wrappers had average compressive strengths of $0.328,0.132$ and $0.100 \mathrm{MPa}$, respectively. On the other hand, the concrete tiles with $15 \%$, 30\% and $45 \%$ partial substitution of pulverized aluminized plastic wrappers had average flexural strengths of $0.262,0.164$, and $0.100 \mathrm{MPa}$, respectively. Generally, the compressive strengths of concrete tiles decreased as the level of partial substitution of pulverized solid waste materials for gravel was increased.

- All concrete tiles with partial substitution of pulverized solid waste materials had numerically/significantly lower flexural and compressive strengths than that of the pure concrete tiles.

- The relationship between the flexural and compressive strengths of concrete tiles and the level of partial substitution of pulverized solid waste materials for gravel were best fitted into non-linear equations:

$$
\begin{gathered}
A F S_{P A W}=0.51-0.1563 L s^{1 / 3} \\
A F S_{P C W}=0.87-0.1718 L s^{1 / 3} \\
1 / A C S_{P A W}=1.880+0.1668 L s \\
1 / A C S_{P C W}=1.587+0.1821 L s
\end{gathered}
$$

- The partial substitution of pulverized solid waste materials for gravel significantly decreased the average material cost of concrete mix. 


\subsection{Recommendations}

Based on the conduct of this study and conclusions drawn, the following recommendations were drawn:

- A follow-up study considering the life span of the concrete tiles with pulverized solid waste materials exposed to continuous loading, heating or cooling, flooding, and other factors should be conducted.

- A follow-up study that will look into the weight reduction, heat transmission and seepage rate of water through concrete tiles made from concrete mixed with pulverized solid waste materials should be conducted.

- Similar studies utilizing the other types of solid waste materials should be conducted.

- A study on varying the proportion of sand mixed with concrete while maintaining the same amounts of concrete, gravel and plastic waste materials should be conducted in order to determine the behavior of the tiles in terms of flexural and compressive strengths.

\section{Acknowledgements}

The researchers would like to express their heartfelt gratitude to the head and staff of the City Engineering Office, Calbayog City, Samar, Philippines, for allowing them to undertake the flexural and compressive strength tests using their Universal Testing Machine.

\section{References}

[1] Derucher, K.N. (1978) Strength. Significance of Tests and Properties of Concrete and Concrete-Making Materials. American Society for Testing and Materials, Philadelphia.

[2] Heiger, R. (1985) Use of Waste Plastics in Cement Concrete Pavement. Dayanada Sagar College of Engineering, Kumaraswamy Layout, Bangalore.

[3] Reynolds, C.E., Steedman, J.C. and Threlfall, A.J. (2007) Reynold’s Reinforced Concrete Designer’s Handbook. 11th Edition, Taylor and Francis, Abingdon.

[4] Shehata, I., Varzavand, S., Eisawy, A. and Fahmy, M. (1996) The Use of Solid Waste Materials as Fine Aggregate Substitute in Cementitious Concrete Composites. Department of Industrial Technology, University of Northern Iowa, Cedar Falls.

[5] www.wikipedia.org/wiki/Paver 